\title{
NEUROMUSCULAR AND CARDIOVASCULAR DEPRESSION PRODUCED BY PROLONGED EXPOSURE TO POLYMYXIN B
}

\author{
A.J.C. de Silva and Chingmuh Lee
}

THE NEUROMUSCULAR BLOCKING PROPERTY Of antibiotics is well recognized. ${ }^{1,2}$ The nature of this undesirable side effect may vary from one antibiotic group to another and even within the same chemical group. ${ }^{3-5}$ Furthermore, the various characteristics of neuromuscular block may change with time when the same drug is used subchronically as opposed to acutely, as has been demonstrated with an aminoglycoside antibiotic neomycin ${ }^{6}$ ( $130-350 \mathrm{mg} / \mathrm{kg}$ over 24 to 48 hours).

Since cases of neuromuscular block encountered clinically tend to be prolonged and, therefore, subchronic, the possible time-dependent change in nature of block has obvious clinical implications. Therefore we studied the characteristics of neuromuscular block produced by acute and subchronic exposure to Polymyxin B, a polypeptide antibiotic well known to cause protracted neuromuscular block ${ }^{1.4}$ which may be difficult to reverse..$^{4.7}$

\section{Merhods}

Six healthy cats of either sex weighing between 2 and $3 \mathrm{~kg}$ were anaesthetized with intraperitoneal $\alpha$-chloralose $75 \mathrm{mg} / \mathrm{kg}$ and pentobarbitone 3 $\mathrm{mg} / \mathrm{kg}$. One common carotid artery, one external jugular vein and the trachea were cannulated. Arterial blood pressure was continuously recorded. Intermittent positive pressure ventilation was delivered by a Palmer pump to maintain normal blood gases according to a normogram previously established for our laboratory (arterial $\mathrm{P}_{\mathrm{CO}_{2}} 3.72-4.66 \mathrm{kPa}$ (28-35 torr); $\mathrm{P}_{\mathrm{O}_{2}} 15.3$ to 16.6 $\mathrm{kPa}(115-125$ torr); $\mathrm{pH} 7.34-7.40)$. The oesophageal temperature was maintained at $37 \pm$ $0.5^{\circ} \mathrm{C}$, whole body warming being applied as needed. The sciatic nerve was exposed at the sciatic notch, severed centrally and stimulated distally with supramaximal square pulses of 0.1 to $0.2 \mathrm{~ms}$ duration. The tibialis anterior muscle was detached from its insertion and attached with

A.J.C. de Silva, M.B., B.S., F.F.A.R.C.S., Anaesthesia Fellow. Chingmuh Lee, M.D., Associate Professor. Department of Anesthesiology, UCLA School of Medicine, Los Angeles, California, 90024.

Address all reprint requests to Dr. C. Lee

Canad. Anaesth. Soc, J., vol. 25, no. 4, July 1978 pre-stretched heavy silk to a Grass FT 10C force transducer. The knee and ankle were immobilized on a heavy metal frame. The force of contraction of the muscle was amplified and recorded on a Gould oscillographic recorder. The nerve-muscle preparation was made bilaterally. The cats were infused with 5 per cent dextrose in lactated Ringer's solution at an approximate rate of $5 \mathrm{ml} / \mathrm{kg} / \mathrm{hr}$, after the initial $20 \mathrm{ml} / \mathrm{kg}$ during the period of stabilization. The preload and length of the muscle necessary for maximal twitch output was determined and maintained for each muscle. This was of the order of 40 to 50 grams.

A five-second $50 \mathrm{~Hz}$ tetanus was elicited to set the preparation and to test its stability. If the base-line tension was altered by this maneuver it was restored. This was repeated till preparation stability was established. Having established preparation stability, a train-of-four, a fivesecond $50 \mathrm{~Hz}$ tetanus and the 10 -second posttetanic twitch were elicited on the left side. The right side was reserved for measurement of drug sensitivity and duration of action and was not tetanized during the experiment. The preparation was again left to stabilize at $0.1 \mathrm{~Hz}$ stimulation.

Polymyxin B, prepared by adding $10 \mathrm{ml}$ of 0.89 per cent saline to $50 \mathrm{mg}$ of the powder, was then injected intravenously to produce a slightly greater than 25 per cent decrease in twitch response. Recovery to exactly 25 per cent block was then allowed at which point a further dose was injected to produce a block greater than 75 per cent without abolishing the twitch. This dose usually ranged from 2 to $3 \mathrm{mg} / \mathrm{kg}$ of Polymyxin B base, depending on the cat. The twitch was then allowed to recover spontaneously to 70 per cent of its control at which point the block was characterized by examining the train-of-four, tetanic and post-tetanic behavior. When the twitch had again reached 75 per cent of its control (measured on the un-tetanized side) the same dose of polymyxin B was repeated. The cycle was repeated up to a maximum of five or six times. The incremental block of twitch produced by each dose, the characteristics of block, and the time for recovery from 75 per cent block to 25 per cent block were measured each time. At the end of the 
first day's observation, $\alpha$-chloralose $50 \mathrm{mg} / \mathrm{kg}$ was infused intravenously to maintain anaesthesia. Then, the preparation was observed overnight with continuing elicitation of twitch at $0.1 \mathrm{~Hz}$. The following morning, approximately 24 hours after the experiment commenced, a small dose of $\alpha$-chloralose ( $20-30 \mathrm{mg} / \mathrm{kg}$ ) was added as needed and the experimental procedure was repeated for one or two cycles. Then a block of over 80 per cent was produced for the last time. On spontaneous recovery to the point of exactly 80 per cent block, freshly prepared 4-aminopyridine s-10 $0.6 \mathrm{mg} / \mathrm{kg}$ was injected intravenously. The return of the twitch to its control and the subsequent overshoot were timed.

\section{RESULTS}

The characteristics of Polymyxin B-induced neuromuscular block did not change with successive doses in any of the parameters examined (Figure 1). The block continued to be charactérized by absence of gross tetanic fade and presence of marked post-tetanic twitch augmentation. The train-of-four ratio remained above 0.65 when measured at the level of 70 per cent block of the twitch, Post-tetanic exhaustion was not seen in any of the experiments. There was also no significant difference in the percentage block of twitch produced by each dose, signifying absence

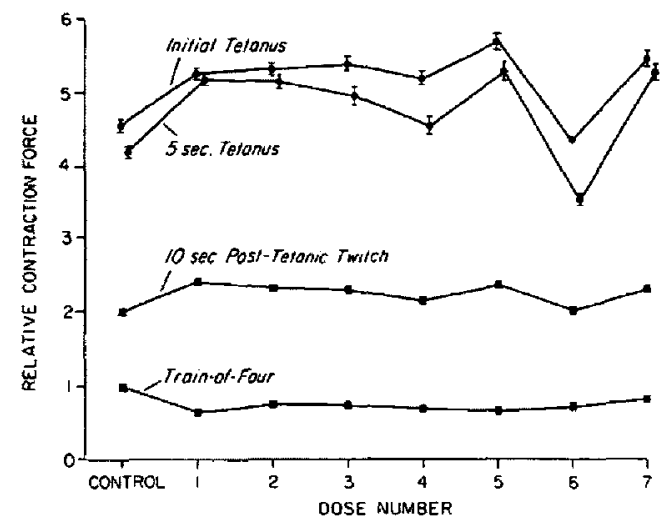

Figure 1 Characteristics of Polymyxin B neuromuscular block during acute and subchronic exposure in the cat examined at the level of 70 per cent block of the twitch. Initial tetanic force, five second tetanic force, 10-second post-tetanic twitch force and the force of the fourth twitch of a train-of-four, were all expressed as a ratio relative to the corresponding single twitch force. Bars indicate standard errors of the mean of six values. The characteristics of block during prolonged exposure remained similar to those of the initial block.

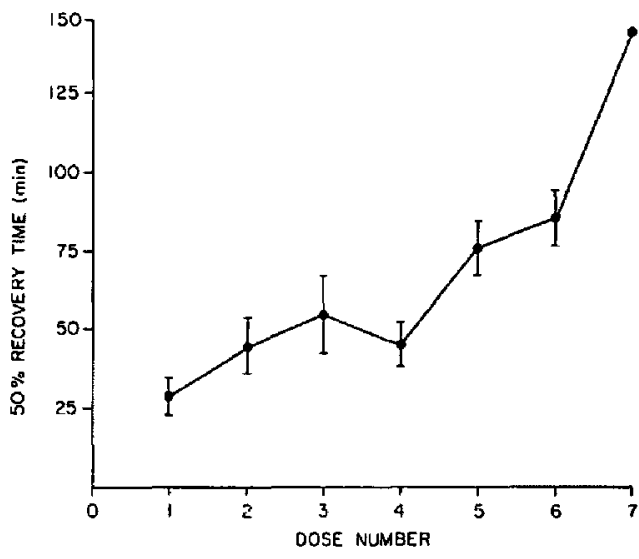

Figure 2 Progressive prolongation of neuromuscular recovery time from successive doses of Polymyxin $B$ in the cat. Bars indicate standard ertors of the mean of 50 per cent recovery time, in minutes.

of change in sensitivity. However, the time for recovery from 25 per cent to 75 per cent of twitch $\left(t_{50}\right)$ showed a significant increase. (Figure 2). Failure of twitch to recover to 75 per cent of control was observed in five cats. In two cats it occurred after the third dose; in the other three it was after the fourth, fifth and sixth dose. In these instances $t_{50}$ was taken as the time of 50 per cent recovery from a lower starting point, e.g., from 15 per cent to 65 per cent of control. The failure of recovery of the twitch continued so that approximately 24 hours later the twitch averaged only 51 per cent (S.E. \pm 5 ) of original control.

The cardiovascular depression caused by polymyxin B is shown in Figure 3.

On injection of 4-aminopyridine rapid reversal was obtained in every case. The time for return of

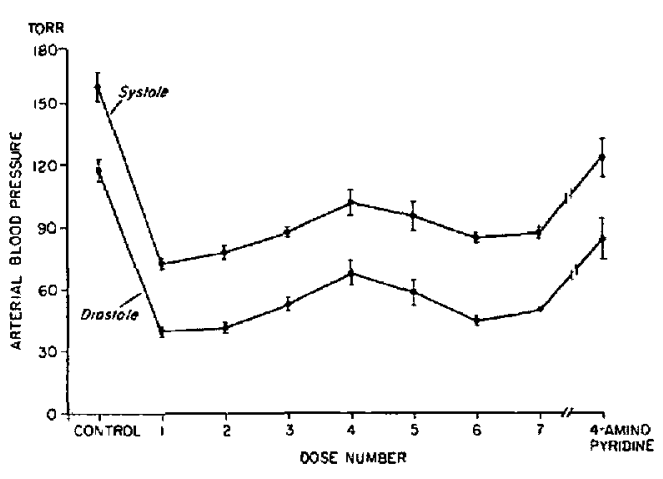

Figure 3 Effect of repeated doses of Polymyxin B on the arterial blood pressure in the cat. Bars indicate standard errors of the mean. Note reversal with 4-aminopyridine $(0.6 \mathrm{mg} / \mathrm{kg})$. 
twitch to second-day control was 17.3 (S.E. \pm 3.5) minutes and the time to attain maximum twitch was 42 (S.E. \pm 5 ) minutes. This maximum twitch was 121 per cent $(S . E . \pm 21$ ) of the second-day control, but only 62 per cent (S.E. \pm II) of the original first-day control.

The initial polymyxin B-induced hypotension persisted but did not progress with successive doses and was also reversed with 4-aminopyridine (Figure 3 ).

\section{Discussion}

Flacke reported in 1972 that subchronic exposure to neomycin resulted in changing characteristics of neuromuscular block. ${ }^{6}$ While the block was initially characterized by stimulus frequency-dependent compensation of block and absence of tetanic fade, the opposite picture (frequency-dependent potentiation of block and tetanic fade) became obvious after subchronic exposure. In other words, the unique characteristics of neomycin-induced neuromuscular block ${ }^{3,6}$ gave way to a curare-like picture.

In all parameters studied, the nature of neuromuscular block produced by polymyxin B did not change during subchronic exposure. After 24 to 30 hours of exposure the characteristics of block remained similar to those observed with the first dose. There is also no evidence of post-tetanic exhaustion. These are among the features distinguishing this antibiotic from neomycin. 3.6 Another feature distinguishing polymyxin $B$ from neomycin and tubocurarine, as has been previously described ${ }^{3,4}$ and hereby confirmed, is slight train-of-four and tetanic fade during acute block (train-of-four ratio $>0.65$ at 70 per cent block) as opposed to absence of fade in the case of neomycin,,$^{3.6}$ and marked fade in the case of tubocurarine (train-of-four near zero at 80 per cent block). The blocking effect (potency) produced by successive doses also remained unchanged. The definite increase in the time for recovery signifies a marked tendency for cumulation of effect, or deterioration of preparation. Progressive failure of muscle twitch depressed by polymyxin B to recover fully to control values has been observed before by us ${ }^{4}$ and by others. * The cause remains to be clarified.

Neuromuscular block produced by polymyxin $B$ is notoriously difficult to reverse, ${ }^{1,2,4,7} \operatorname{Re}$ -

*Personal communication: 1. Ronald Miller, M.D. University of California, San Francisco. 2. Francis F. Foldes, M.D., Montefiore Hospital, New York. cently the ability of 4-aminopyridine to completely reverse neuromuscular block produced by acute administration of polymyxin $B$ has been repoited. ${ }^{10}$ The persistence of this property during sub-chronic exposure again denotes a new potential clinical use for this drug.

In conclision, the neuromuscular block produced by polymyxin $B$ does not change during subchronic exposure. 4-Aminopyridine effectively reverses the neuromuscular and cardiovascular depression following subchronic, as well as acute exposure.

\section{SUMMARY}

It has been reported previously that in cats pre-treatment for 24 to 48 hours with neomycin sulphate resulted in a change in the pattern of neuromuscular block subsequently produced with this antibiotic. The unique characteristics of neomycin-induced neuromuscular block observed during acute exposure gave way to a pattern of block usually observed with tubocularine. In a similar experiment on six cats we have demonstrated that with polymyxin B prolonged exposure did not result in a comparable timedependent change in the nature of the neuromuscular block it produced, in terms of train-offour, tetanic, and post-tetanic behaviour of the neurally-elicited muscle response. The differing characteristics of neuromuscular block seen with various antibiotics, e.g. the aminoglycoside neomycin as opposed to the polypeptide polymyxin B, during acute and sub-chronic exposure is stressed. Previously observed ability of $4 \mathrm{ami-}$ nopyridine $0.6 \mathrm{mg} / \mathrm{kg}$ to reverse the neuromuscular and cardiovascular depression during acute exposure to polymyxin $\mathbf{B}$ persisted in prolonged exposure.

\section{RÉSUMÉ}

Flacke a démontré chez le chat, en 1972, que le bloc neuro-musculaire secondaire à l'administration de néomycine changeait de caractère après 24 à 48 heures d'administrations répétées du médicament, passant d'un bloc typique à la néomycine à un bloc semblable à celui produit par la tubocurarine. Nous avons effectué une étude du mẽme genre avec la polymyxine $B$, dans le but de vérifier si les caractéristiques du bloc se modifiaient après des doses répétées. L'étude a porté sur le chat, six préparations animales étant utilisées.

Le bloc produit par la polymyxine ne change 
pas avec le temps. Le temps de récupération augmente avec les doses successives. La 4 aminopyridine renverse ce bloc, de même que la dépression cardiovasculaire causée par le médicament. Ce bloc est donc différent de celui secondaire à la néomycine.

\section{REFERENCES}

I. Pittinger, C.B., Eryasa, Y., \& Adamson, R. Antibiotic-induced paralysis. Anesth. Analg. 49: $487(1970)$

2. Pintinger, C.B. \& Adamson, R. Antibiotic blockade of neuromuscular function. Ann. Rev. Pharmacol. 12: 169 (1972).

3. Lee, C., Chen, D., Barnes, A., \& Katz, R.L. Neuromuscular block by neomycin in the cat. Canad. Anaesth. Soc. J. 23: (5) 527 (1976).

4. LeE, C., Chen, D.\& NAgel, E.L. Neuromuscular block by antibiotics: Polymyxin B. Anesth. Analg. $56: 373$ (1977).

5. Wright, J.B. \& Colluer, B. The effects of neomycin upon transmitter release and action. $J$. Pharmacol. Exp. Ther. 200: 576(1977).
6. FLACKE, W.E. Acute and subchronic effects of Neomycin on neuromuscular transmission. V. International Congress on Pharmacology, San Francisco, p. 69 (1972).

7. Van Nyhuis, L.S., Miller, R.D., \& Fogdall, R.P. The interaction between d-tuborucarine, pancuronium, polymyxin $B$, and neostigmine on neuromuscular function. Anesth. Analg. 55: 224 (1976).

8. Schauf, C.L., Colton, C.A., Colton, J.S., \& Davis, F.A. Aminopyridines and sparteine as inhibitors of membrane potassium conductance: effects on myxicola giant axon and the lobster neuromuscular junction. J. Pharmacol. Exp. Ther. 197: 412 (1976).

9. Yeh, J.Z., OXFord, G.S., Wu, C.H., \& Narashi, $T$. Interactions of aminopyridines with potassium channels of squid axon membranes. Biophysic J. 16: 77 (1976).

10. Lee, C., de Silva, A.J.C. \& Katz, R.L. Antagonism of polymyxin B-induced neuromuscular and cardiovascular depression by 4-aminopyridine in the anesthetized cat. Anesthesiology (accepted for publication). 